\title{
CASE STUDY ON AN APPROACH TO THE MANAGEMENT OF LOCALLY ADVANCED CARCINOMA OF BREAST
}

\author{
Puthamakula Sreenivasa ${ }^{1}$, Rita Singh², Stalin Kampelly33, Avinash Gottumukkala ${ }^{4}$
}

${ }^{1}$ Associate Professor, Department of General Surgery, MNR Medical College and Hospital, MNR Nagar, Sangareddy. ${ }^{2}$ Assistant Professor, Department of General Surgery, MNR Medical College and Hospital, MNR Nagar, Sangareddy. ${ }^{3}$ Postgraduate Student, Department of General Surgery, MNR Medical College and Hospital, MNR Nagar, Sangareddy. 4 Postgraduate Student, Department of General Surgery, MNR Medical College and Hospital, MNR Nagar, Sangareddy.

\section{ABSTRACT}

\section{BACKGROUND}

\section{Locally Advanced Carcinoma Breast}

Breast cancer is one of the most common malignancies in female and in developing countries, majority of them present in locally advanced stages. Patients presenting with LABC constitute a diverse group for which a variety of treatment modalities have be en instituted with co-ordinated treatment planning among the medical oncologist, surgical oncologist and radiation oncologist. The study is conducted to know the incidence, age distribution and common modes of presentation.

\section{MATERIALS AND METHODS}

This is a prospective study of 50 patients presenting with Stage III and inflammatory breast cancer to MNR Medical College and Hospital, Department of General Surgery from December 2014 to December 2015.

\section{RESULTS}

Majority of the patients, 35 (70\%) of the patients were doing well at the end of the study. The most distressing outcome was development of distant metastasis in $4(8 \%)$ of the patients. These cases included one inflammatory carcinoma and other three were Stage IIIB, two of which had not responded to NACT and had remained inoperable. Local recurrence was seen in 3 (6\%) of the patients. Two of these cases were of Stage IIIA and was not on radiotherapy. One case belonged to Stage IIIB and had completed radiotherapy; 8 (16\%) of the cases were lost to followup.

\section{CONCLUSION}

Multimodality therapy is effective in treatment of locally advanced carcinoma of breast, but distant metastasis is seen in four patients and local recurrence in 3 patients shows that management is still a challenge and improvements in current therapies and newer modalities are needed to further reduce disease free and overall survival.

\section{KEYWORDS}

Locally Advanced Breast Carcinoma, Neoadjuvant Chemotherapy.

HOW TO CITE THIS ARTICLE: Sreenivasa P, Singh R, Kampelly S, et al. Case study on an approach to the management of locally advanced carcinoma of breast. J. Evolution Med. Dent. Sci. 2017;6(21):1714-1719, DOI: 10.14260/Jemds/2017/377

\section{BACKGROUND}

Worldwide breast cancer is the most frequent cancer in women and represents the second leading cause of cancer death among women (after lung cancer).1,2 Locally Advanced Breast Cancer (LABC) constitutes more than $50 \%$ to $70 \%$ of the patients presenting for treatment. 3

The Locally Advanced Breast Cancer (LABC) is characterised by varying clinical presentations such as presence of a large primary tumour $(>5 \mathrm{~cm})$ associated with or without skin or chest wall involvement or with fixed (matted) axillary lymph nodes or with disease spread to the ipsilateral internal mammary or supraclavicular nodes in the absence of any evidence of distant metastases. These are tumours belonging to Stages IIIA, IIIB, IIIC and inflammatory breast cancer.

Financial or Other, Competing Interest: None.

Submission 09-12-2016, Peer Review 01-03-2017,

Acceptance 07-03-2017, Published 13-03-2017.

Corresponding Author:

Dr. Puthamakula Sreenivasa,

Villa No. 19, Elite Villa, Kollur (Village),

R. C. Puram (Mandal), Medak District.

E-mail:drsreenivasms@yahoo.com

DOI: $10.14260 /$ jemds $/ 2017 / 377$
Although, the clinical features at presentation and prognosis among women with LABC vary, there are two common problems in the treatment. Achieving local control and prolonging survival by preventing or delaying distant metastasis.

Today treatment of LABC requires a combination of systemic and local/regional therapies.

\section{Chemotherapy Regimens \\ CMF}

Cyclophosphamide $500 \mathrm{mg} / \mathrm{m} 2$, Methotrexate $50 \mathrm{mg} / \mathrm{m} 2$ and 5 fluorouracil $500 \mathrm{mg} / \mathrm{m} 2$.

All three drugs IV day 1 and day 8 every 4 weeks for 6 cycles (includes pre-op and post-op).

AC

Adriamycin $60 \mathrm{mg} / \mathrm{m} 2$, Cyclophosphamide $600 \mathrm{mg} / \mathrm{m} 2$.

Both IV day 1 every 3 weeks for 4 cycles (includes pre-op and post-op).

AC for 4 cycles followed by paclitaxel $175 \mathrm{mg} / \mathrm{m} 2$ every 3 weeks for 4 cycles (includes pre-op and post-op).

\section{Surgery 4}

Modified radical mastectomy implies removal of entire breast tissue from clavicle to rectus abdominis and between sternal 
edge and latissimus dorsi together with nipple areolar complex, excess skin of the breast and fascia of pectoralis major muscle. It includes axillary dissection.

\section{Prognostic Indicators}

Axillary lymph nodes- The extent of axillary lymph node involvement by breast cancer is the most established and reliable prognostic factor for subsequent metastatic disease and survival.

\section{The other factors are-}

- Tumour size.

- Histologic grading.

- $\quad$ ER/PR status.

- Age- Very young (35 years or less) breast cancer patients have poorer prognosis than older patients.

- HER-2 amplification or overexpression, poorer prognosis.

\section{Objective}

The study is conducted to know the incidence, age distribution, common modes of presentation. To study the multimodality management including neoadjuvant chemotherapy, surgery and adjuvant therapies.

\section{MATERIALS AND METHODS}

This is a prospective study of 50 patients presenting with Stage III and inflammatory breast cancer to MNR Medical College and Hospital, Department of General Surgery from December 2014 to December 2015.

\section{Sample Size- 50 patients.}

\section{Inclusion Criteria}

All patients presenting in MNR Hospital, Sangareddy with Stage IIIA, IIIB, IIIIC and inflammatory carcinoma were included in the study.

\section{Exclusion Criteria}

Patients who were clinically diagnosed as having locally advanced breast cancer (i.e. IIIA, IIIB, IIIC and inflammatory carcinoma), but on investigations found to have distant metastasis were excluded.

\section{Anatomy}

\section{Extent}

The breasts are modified sweat glands, which extend from the level of second to sixth rib. It extends transversely from the lateral border of the sternum to the anterior axillary line. ${ }^{5}$ The deep surface of the breast rests on the fascia of the pectoralis major, serratus anterior and external oblique abdominal muscles. The axillary tail of Spence extends laterally across the anterior axillary fold.

\section{Blood Supply}

The breast receives its principal blood supply from-

1. Perforating branches of the internal mammary.

2. The lateral thoracic artery is a branch of axillary artery and courses along the lateral border of pectoralis minor muscle.

3. The pectoral branch of the acromiothoracic artery, also a branch of axillary artery, this supplies the posterior part of the breast.

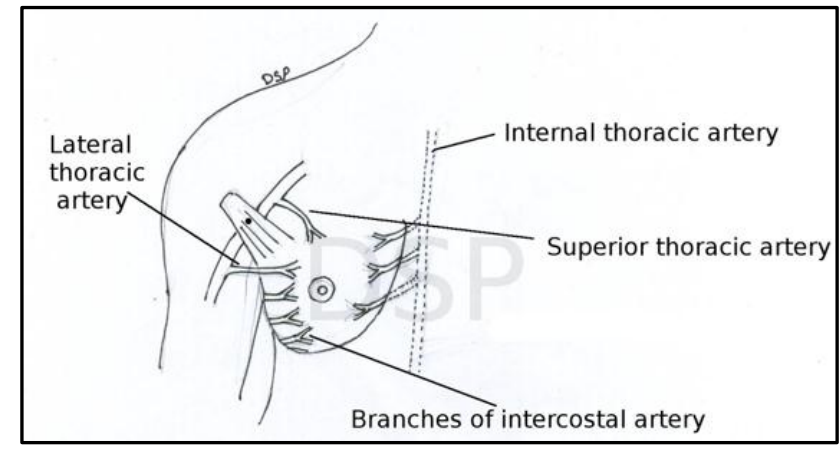

Blood Supply of Breast

\section{Venous Drainage}

Can broadly be classified into deep veins and superficial veins.

A. The deep veins of the breast drain along routes of corresponding arterial supply, so major drainage is via perforating veins into the internal mammary veins.

B. The superficial veins are quite rich and sometimes dilated during pregnancy and neoplasm. The majority of these veins drain into the internal mammary vein and axillary vein.

\section{Nerve Supply}

Lateral cutaneous branches of third through sixth intercostal nerves provide sensory innervations of the breast (lateral mammary branches) and of the anterolateral chest wall. Cutaneous branches that arise from cervical plexus, specifically the anterior branches of the supraclavicular nerve supply a limited area of skin over the upper portion of the breast.

\section{Lymphatic Drainage of Breast6}

Group 1- External mammary nodes or anterior pectoral nodes.

Group 2- Scapular nodes.

Group 3- Central nodes.

Group 4- Interpectoral nodes (Rotter's nodes). These lie between the pectoralis major and minor muscles.

Group 5- Axillary vein nodes.

Group 6- Subclavicular nodes.

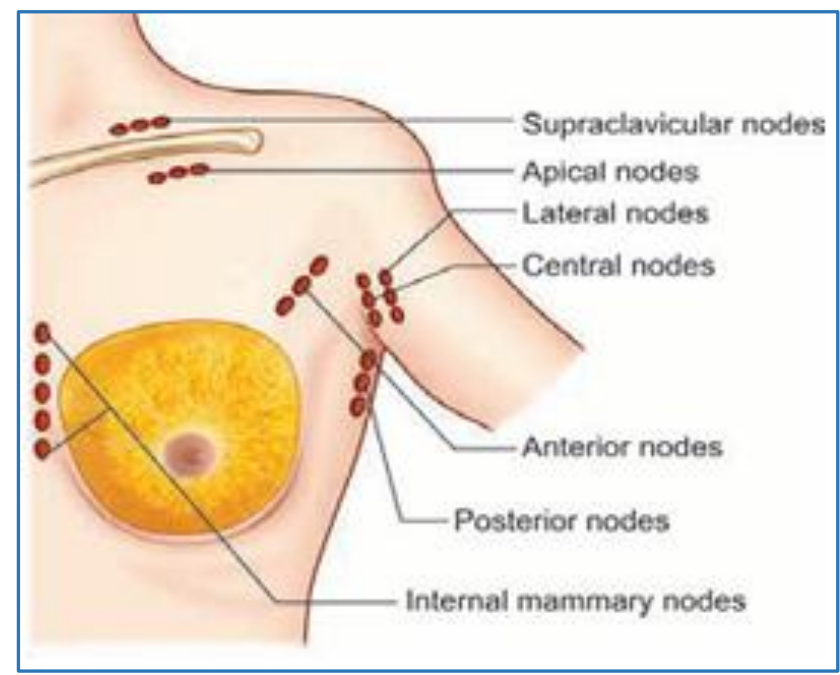




\section{RESULTS}

\section{Proportion of Cases}

The total number of patients with carcinoma breast admitted during the study period was 136. Out of these, 60 patients were identified as patients of LABC based on the accepted definition. Thus $44 \%$ of patients admitted with carcinoma breast presenting for treatment were identified as patients with LABC.

\section{Age Distribution}

The age of the presenting patients ranged from 27 to 65 years. The highest number of patients were in age group of 41 - 50 years' age group with 17 (34\%) followed by 31 - 40 years' age group with $13(26 \%)$. The mean age of patients was 45.1 years.

\section{Duration of Symptoms}

The highest number of patients had symptoms for $3-6$ months, i.e. 19 (38\%). The duration of symptoms ranged from 1 - 28 months. The mean duration of symptoms was found to be 8.84 months.

\section{Symptoms at Presentation}

Lump is the most consistent symptom and present in all the patients; $8(16 \%)$ of these patients presented with an ulcer over the lump. Pain was the complaint in $13(26 \%)$ of the patients; $6(12 \%)$ patients complained of lump in the ipsilateral axilla.

\begin{tabular}{|c|c|c|}
\hline Symptom & Number of Cases & $\mathbf{\%}$ \\
\hline Lump & 50 & $100 \%$ \\
\hline Ulcer with Lump & 8 & $16 \%$ \\
\hline Pain & 13 & $26 \%$ \\
\hline Retraction of Nipple & 14 & $28 \%$ \\
\hline Nipple Discharge & 6 & $12 \%$ \\
\hline Swelling in Axilla & 6 & $12 \%$ \\
\hline \multicolumn{2}{|c|}{ Table 1. Symptoms at Presentation } \\
\hline \multicolumn{2}{|c}{} \\
\hline
\end{tabular}

\section{Quadrants Involved}

The upper outer quadrant is the most common predominantly involved quadrant with a total of 29 (58\%) cases. Since most of the lumps were large, they spanned more than one quadrant.

\begin{tabular}{|c|c|c|}
\hline $\begin{array}{c}\text { Predominantly } \\
\text { Involved Quadrant }\end{array}$ & $\begin{array}{c}\text { Number of } \\
\text { Cases }\end{array}$ & Percentage \\
\hline Upper Outer & 29 & $58 \%$ \\
\hline Upper Inner & 5 & $10 \%$ \\
\hline Lower Outer & 8 & $16 \%$ \\
\hline Lower Inner & 3 & $6 \%$ \\
\hline Central & 5 & $10 \%$ \\
\hline \multicolumn{2}{|c|}{ Table 2. Quadrants Involved } \\
\hline
\end{tabular}

\section{Tumour Size}

The tumour size ranged from $4 \mathrm{~cm}$ to $12 \mathrm{~cm}$ in the highest dimension. The smallest tumour measured $4 \times 3 \mathrm{cms}$, while the largest $12 \times 10 \mathrm{cms}$. Majority of the tumours were $5-8$ $\mathrm{cms}$ size. The mean size of the tumours is $6.6 \mathrm{cms}$.

One patient presenting with inflammatory carcinoma had diffuse lump.

\section{Fixity to Skin and Chest Wall}

$24(48 \%)$ of 50 cases were found to have fixity to either skin or chest wall. Highest number 12 (24\%) were found to have Peau d'orange implying skin fixity and $8(16 \%)$ had ulcer over the lump. Chest wall fixity was found in $5(10 \%)$ cases.

\begin{tabular}{|c|c|c|c|}
\hline Fixity & Feature & $\begin{array}{c}\text { Number of } \\
\text { Patients }\end{array}$ & $\mathbf{\%}$ \\
\hline & Peau d'orange & 12 & $24 \%$ \\
\hline Skin & Ulcer & 8 & $16 \%$ \\
\hline & Sat Nodule & 1 & $2 \%$ \\
\hline Chest Wall & \multicolumn{3}{|c|}{ Table 3. Fixity to Skin and Chest Wall } \\
\hline \multicolumn{2}{|c|}{}
\end{tabular}

\section{Lymph Node Status}

The axillary node status seen in the study is depicted in the following table and graph.

\begin{tabular}{|c|c|c|}
\hline $\begin{array}{c}\text { Lymph Node } \\
\text { Status }\end{array}$ & $\begin{array}{c}\text { Number of } \\
\text { Patients }\end{array}$ & Percentage \\
\hline N1 & 26 & $52 \%$ \\
\hline N2 & 22 & $44 \%$ \\
\hline N3 & 2 & $4 \%$ \\
\hline \multicolumn{2}{|c|}{ Table 4. Lymph Node Status } \\
\hline
\end{tabular}

\section{Stage of the Disease}

24 of the 50 cases studies 23 (46\%) were of Stage IIIA, 24 $(48 \%)$ are Stage IIIB, 2 cases (4\%) are Stage IIIC and 1 case $(2 \%)$ is inflammatory carcinoma.

\begin{tabular}{|c|c|c|c|c|}
\hline Group & TNM & Number of & Number of & $\%$ \\
\hline Stage & Stage & Patients & Patients & \\
\hline IIIA & T3N1M0 & 12 & & \\
\hline & T3N2M0 & 10 & 23 & $46 \%$ \\
\hline & T2N2 & 1 & & \\
\hline IIIB & T4aN1M0 & 1 & 24 & $48 \%$ \\
\hline & T4aN2M0 & 4 & & \\
\hline & T4bN1M0 & 13 & & \\
\hline & T4bN2M0 & 6 & & \\
\hline IIIC & T3N3M0 & 2 & 2 & $4 \%$ \\
\hline $\begin{array}{c}\text { Inflammatory } \\
\text { Ca }\end{array}$ & T4d & 1 & 1 & $2 \%$ \\
\hline \multicolumn{5}{|c|}{ Table 5. Stage of the Disease } \\
\hline
\end{tabular}

\section{Chemotherapy Regimen}

Three standard regimen were used in the study. CMF was used the most in $26(52 \%)$ of the patients. AC regimen was used in 24 (48\%).

\section{Response to Neoadjuvant Chemotherapy}

Response to neoadjuvant chemotherapy was assessed by calculating the percentage decrease in the volume of the tumour.

In our study of the 38 patients who received neoadjuvant chemotherapy, $5(13.2 \%)$ patients had complete clinical response (cCR), $25(65.8 \%)$ patients had partial clinical response (pCR); 8 (21\%) had stable disease. One case of inflammatory carcinoma had no response to therapy.

Proportion of Inoperable Tumours Converted to Operable Stages

$38(76 \%)$ cases presenting as inoperable were subjected to NACT, of these 35 were converted to operable and only 3 
remained inoperable. These tumours which remained inoperable were subjected to radiotherapy.

\section{Receptor Status}

Both ER and PR were positive in 23 (46\%) of the cases, both ER/PR were negative in 20 (40\%). ER positivity with PR negativity was seen in $5(10 \%)$. ER negativity with PR positivity was seen in 2 (4\%). Overall receptor positivity is seen in $30(60 \%)$ patients. Tamoxifen $20 \mathrm{mg}$ O.D for 5 years was advised to all patients with hormone receptor positive status.

\section{Histopathology}

Infiltrating intraductal carcinoma was the predominant type seen in $46(92 \%)$ of the patients. Other types seen were 1 (2\%) each of Medullary, Colloid, Lobular and Inflammatory types.

\section{Outcome}

The patients were regularly followed up and at the end of the study $35(70 \%)$ of the patients were doing well; $4(8 \%)$ of the patients developed distant metastasis and $3(6 \%)$ of the patients developing local recurrence; $8(16 \%)$ of the patients were lost to followup.

\section{DISCUSSION}

\section{Proportion of Cases}

In our hospital, $44 \%$ of the patients admitted for the treatment of breast cancer were locally advanced. Chopra $\mathrm{R}$ states the proportion of LABC to the total number of reported breast cases to be $28.9 \%, 40.5 \%$ and $52 \%$ in Mumbai, Trivandrum and Chennai respectively.

\section{Age Distribution}

The highest number of cases are seen in the age group of 41 50 years in all the studies including ours.

The mean age is 46.5 years and 47.39 years in Amit Aggarwal et $\mathrm{al}^{7}$ and D S Sandhu et $\mathrm{l}^{8}$ series respectively. The mean age in our study, i.e. 45.1 years matches closely with the above-mentioned studies.

In general, breast cancer has been reported to occur a decade earlier in Indian patients compared to their Western counterparts. While the majority of breast cancer patients in Western countries are postmenopausal and in their $60 \mathrm{~s}$ and $70 \mathrm{~s}$, the picture is quite different in India with premenopausal patients constituting about 50\% of all patients. ${ }^{9}$

\section{Symptoms at Presentation}

The presenting features are compared with the percentages of presenting features in some of the similar series from India. The most consistent symptom is that of a lump and is seen in all cases in our study and $87.9 \%, 74 \%, 96.5 \%$ in Sandhu D S et al, Gang et al and Raina et al series respectively.

\section{Quadrants Involved}

In all the series, the percentage in the upper outer quadrant by far exceeds the percentage of location in other quadrants. The percentages of lump in the upper outer quadrants are $58 \%, 47 \%, 49 \%$ and $48 \%$ in the current, Sandhu DS et al, Sen and Dasgupta et al and Fields et al series.
The possible explanation is that the upper outer quadrant has a relatively larger volume of breast tissue.

\section{Duration of Symptoms}

Most of the cases present with 3 - 6 months' duration. The percentage of patients in this range was $38 \%$ and $32.9 \%$ in our study and in D S Sandhu et al series respectively. The cases with less than 3 months' duration were higher in D S Sandhu series compared to our study.

\section{Tumour Size}

The tumour sizes in our study are compared with Chintamani et al and Aggarwal Himanshu et al studies. Maximum tumours are in the range of $5-8 \mathrm{cms}$. The percentage of tumours in that range is considerably higher in our study.

The patients ignore the mass, as it is commonly painless and does not interfere with the regular lifestyle of the patient. There is also considerable delay in presenting to the hospitals due to ignorance allowing the lump to attain larger proportions.

\section{Lymph Node Status}

Jai Ganesh Vishambaran L K et al reported N1 stages to be $93 \%$ and N2 stages to be $7 \%$. Compared to this study, our patients showed a higher incidence of N2 disease. But results similar to ours were seen in series of Chintamani et al and Aggarwal Himanshu et al. The percentages are shown in the above table.

\section{Stage of the Disease}

In the present study more percentage of cases were of IIIB (48\%) than stage IIIA (46\%); $4 \%$ and $2 \%$ of cases were of IIIC and inflammatory carcinoma.

Jaiganesh Vishambaran L K et al have reported 70\% IIIA and $30 \%$ IIIB stages among their patients.

The percentages for IIIA were 24\%, 55\% and 27.2\% respectively in B S Yadav et al, William $\mathrm{G}$ et al and Brian Nolen et al.

Stage IIIB cases were $33 \%, 27 \%$ and $36.4 \%$ respectively in B S Yadav et al, William G et al and Brian Nolen et al.

IIIC cases were reported in BS Yadav et al and William G et al with $25 \%$ and $2 \%$ of cases respectively.

\section{Response to Neoadjuvant Chemotherapy}

$38(76 \%)$ patients who presented in operable states were subjected to neoadjuvant chemotherapy. CMF and an anthracycline based regimen AC were used.

The primary objectives of neoadjuvant chemotherapy is to downstage the tumours and in cases of inoperable tumours to convert them into operable ones. In our study also maximum number of cases 25 of $38(65.8 \%)$ had partial response.

The rates of partial response were $45.45 \%, 65 \%, 73 \%$ and $56.3 \%$ in Brian Nolen et al, B S Yadav et al, Jaiganesh Vishambaran L K et al and Amit Aggarwal et al respectively.

In their article, Nirmal Raut and Nilesh Chordiya present data related to response rates of various trials. ${ }^{10}$

Our data compares closely with the results mentioned in the above table.

\section{Conversion Rates of Inoperable Tumours}

Out of 38 inoperable tumours treated with neoadjuvant chemotherapy, 35 were rendered operable. Thus, $92 \%$ of 
inoperable tumours were converted to operable ones. This data shows that in our study fairly good objective response to neoadjuvant chemotherapy was seen and that neoadjuvant chemotherapy downstages a good number of tumours and makes them operable and gives better locoregional control.

\section{Receptor Status}

Receptor status of our study compares closely with the results of receptor status study by Tanuja Shet et al conducted at Tata Memorial Hospital, Mumbai from 1999 to 2006. The receptor positivity is $60 \%$ in our population and $55.8 \%$ in Tanuja Shet et al study.

\section{Complications of Therapy}

Toxicity of Chemotherapy regimen. The toxicities of chemotherapy noted in our study are compared with study conducted by Sambasivaiah Kurapathy ${ }^{11}$ et al. In both the studies, overall the toxicity rates are higher in anthracycline based regimen like AC than in CMF. Most common adverse effect noted is alopecia followed by emesis and anaemia in AC regimen and anaemia and mucositis in CMF regimen. Neutropenia was noted in only one patient on AC regimen. The rates of toxicity are comparable to the above-mentioned study.

\section{Outcome}

Majority of the patients, 35 (70\%) of the patients were doing well at the end of the study. The most distressing outcome was development of distant metastasis in $4(8 \%)$ of the patients. These cases included one inflammatory carcinoma and other three were stage IIIB, two of which had not responded to NACT and had remained inoperable.

Local recurrence was seen in $3(6 \%)$ of the patients. Two of these cases were of Stage IIIA and was not on radiotherapy. One case belonged to Stage IIIB and had completed radiotherapy.

$8(16 \%)$ of the cases were lost to followup.

\section{CONCLUSION}

- About half of the cases presenting with breast cancer are in locally advanced stages.

- Lump in the breast is the most common symptom, upper outer quadrant being its most common location and most of the lumps were 5 - $8 \mathrm{cms}$ in size.

- Highest number of cases were presented in 5th decade followed by 4 th decade indicating the presentation is a decade earlier in Indian patients compared to the West.

- Fixity to skin was seen in about $48 \%$ of the cases and was the most common cause of inoperability.

- Only a quarter of the cases were operable, rest inoperable.

- $\quad$ Patients administered NACT showed good response with $13.2 \%$ and $65.8 \%$ of the patients showed clinically complete and partial response respectively; $92 \%$ of inoperable tumours became operable confirming that NACT is an effective method of down staging the tumour.

- Infiltrating ductal carcinoma is overwhelmingly the most common histological variant seen.

- Multimodality therapy is effective in treatment of locally advanced carcinoma of breast, but distant metastasis is seen in four patients and local recurrence in 3 patients shows that management is still a challenge and improvements in current therapies and newer modalities are needed to further reduce disease free and overall survival.

\section{SUMMARY}

- A very high number of cases, $44 \%$ presented in locally advanced stage of breast cancer in tune with trend in developing countries.

- Highest incidence was seen in 5th decade with 17 (34\%) of patients presenting in this age group followed by 4th decade with 13 (26\%) of patients. Mean age being 45.1 years.

- Lump in the breast is the overwhelmingly common presentation and was seen in all the patients; the most common location of the tumour being upper outer quadrant 29 (58\%).

- Most of the patients 19 (38\%) present with duration of symptoms from 3 to 6 months with mean duration being 8.8 months.

- $\quad$ Size of $75 \%$ of tumours were in range of $5-8 \mathrm{cms}$ with mean size being $6.6 \mathrm{cms}$.

- Fixity to skin and chest wall was seen in $38 \%$ and $10 \%$ of cases respectively, making them inoperable at presentation; $24 \%$ of cases were operable at presentation and $76 \%$ inoperable.

- $46 \%$ presented in Stage IIIA, $44 \%$ presented in Stage IIIB and $4 \%$ in Stage IIIC and 2\% inflammatory breast cancer.

- Neoadjuvant chemotherapy was administered to these all inoperable cases converting $92 \%$ of these to operable stages. Clinical complete response was seen in $13.2 \%$, clinical partial response seen in $65.8 \%$ and $21 \%$ had stable disease.

- Chemotherapy was well tolerated in patients with alopecia being most common toxicity.

- $60 \%$ of patients are hormone receptor positive.

- Infiltrating ductal carcinoma is by far the most common histopathological variant seen in $92 \%$ of patients.

\section{REFERENCES}

[1] Dumitrescu RG, Cotarla I. Understanding breast cancer risk-where do we stand in 2005? J Cell Mol Med 2005;9(1):208-21.

[2] Chandra AB. Problems and prospects of cancer of the breast in India. J Indian Med Assoc 1979;72(2):43-5.

[3] Chopra R. The Indian scene. J Clin Oncol 2001;19(18 Suppl):S106-111.

[4] DeVita VT, Lawrence TS, Rosenberg SA. DeVita, Hellman, and Rosenberg's Cancer: principles and practice of oncology. Vol 2. Lippincott Williams and Williams, 2008.

[5] Skandalaski JE. Skandalaski's surgical anatomy: the embryologic and anatomic basis for modern surgery. McGraw Hill companies, 2004.

[6] National Cancer Registry Program. Ten year consolidated report of the Hospital Based Cancer Registries, 1984-1993, an assessment of the burden and care of cancer patients. Indian Council of Medical Research, New Delhi, 2001.

[7] Sandhu DS, Sandhu S, Karwasra RK, et al. Profile of breast cancer patients at a tertiary care hospital in north India. Indian J Cancer 2010;47(1):16-22. 


\section{Jemds.com}

[8] Aggarwal H, Lubana PS, Jain DK, et al. Estimation of BCL-2 protein in carcinoma of the breast and its clinical correlation in locally advanced breast cancer. J Cancer Res Ther 2007;3(4):207-10.

[9] Raut NV, Chordiya N. NEO adjuvant chemotherapy in breast cancer: what have we learned so far? Indian J Med Paediatr Oncol 2010;31(1):8-17.

\section{Original Research Article}

[10] Kuraparthy S, Reddy KM, Yadagiri LA, et al. Epidemiology and patterns of care for invasive breast carcinoma at a community hospital in Southern India. World J Surg Oncol 2007;5:56. 